\title{
Factoring transition risks into regulatory stress-tests: The case for a standardized framework for climate stress testing and measuring impact tolerance to abrupt late and sudden economic decarbonization
}

\author{
Michael Hayne*,1, Soline Ralite ${ }^{2}$, Jakob Thomä ${ }^{1}$, Daan Koopman ${ }^{1}$ \\ ${ }^{1} 2^{\circ}$ Investing Initiative, Berlin, Germany \\ ${ }^{2} 2^{\circ}$ Investing Initiative, Paris, France
}

\section{ARTICLE INFO}

\section{Article history:}

Received 17 April 2019

Revised 29 November 2019

Accepted 5 December 2019

Published 7 January 2020

\section{Keywords:}

Climate stress-test

Climate transition risks

Scenario analysis

Reverse stress-testing

Minsky moment

\begin{abstract}
A debate has recently emerged as to whether climate risks may be material for financial stability, driven by a solid body of evidence that climate risks may create value destruction for key industrial sectors that are prominently represented in financial markets. As a result, financial supervisory authorities are starting to explore how these risks can be integrated into existing stress-testing frameworks. This paper proposes a methodology that financial supervisors could follow to build 'late \& sudden' transition scenarios that could be used as input into either traditional or climate-specific stress-tests of regulated entities. It also proses that supervisors run multiple simulations of these scenarios across regulated entities to inform on systemic and idiosyncratic 'impact tolerance' and creation of 'reverse stress-tests' enable the setting of minimum capital thresholds. An illustrative application of the process is shown, focusing on listed equity and corporate bonds tied to climate sensitive sectors (fossil fuels, power, steel, cement, automotive and aviation).
\end{abstract}

\section{Introduction}

In order for global temperatures to stay below $+1.5^{\circ}$ above pre-industrial era by the end of the century, estimates suggest that $\$ 2.4$ trillion would have to be invested annually until 2035 for the transition of the industrial, energy, agricultural, residential and transport sectors (IPCC, 2018). Similarly, a significant amount of capital will need to be moved out of current high-carbon investments in a range of sectors, including fossil-fuel mining, utilities, certain types of high-carbon manufacturing, and transport infrastructure. These necessary shifts in global financing flows will give rise to a new set of financial risks associated with the transition to a low-carbon economy. Failing to anticipate these so called "energy transition" risks might lead to large-scale mispricing of carbon-intensive assets (De Greiff et al., 2018), inevitably followed by sudden repricing when the market finally realizes the depth of the transition to come.

In the speech that he gave to the European Commission on March 21th 2019, Mark Carney, the governor of the Bank of England, highlighted the need for financial supervisors to conduct climate stress-tests to assess the resilience of their regulated entities to such risks, and specifically to consider the eventuality of a "Climate Minsky moment", i.e. a sudden materialization of climate risks. Similarly, the European Systemic Risk Board (ESRB) recommended

This report was supported by the International Climate Initiative (IKI) through project grant 18_I_351_Global_A_Paris and financial markets. The Federal Ministry for the Environment, Nature Conservation and Nuclear Safety (BMU) supports this initiative on the basis of a decision adopted by the German Bundestag.

* Corresponding author.

E-Mail address: michael@2degrees-investing.org

ORCID: 0000-0003-4506-1010 
exploring how transition risks could be integrated into mainstream banking stress-testing frameworks (ESRB, 2016), and described in its scientific advisory board's report "Too late, too sudden?" (2016) how a "late \& sudden" transition scenario could impact overall financial stability.

The aim of this paper is outline why current stress tests do not capture the nature of true "late \& sudden" economic decarbonization and calls for a new approach and suggests framework to meet this objective. It provides financial supervisors with a methodology to build a range of late $\&$ sudden transition scenarios to input either in traditional or climate-specific stress-tests of regulated entities. It also suggests methods for how the results could be consolidated to inform 'reverse stress-testing', creating test procedures that target the vulnerably of current portfolio holdings for the purpose of understand key risk drivers to inform creation of early warning systems or minimum capital requirements.

The methodology specifically focuses on equity and corporate bonds tied to climate sensitive sectors (fossil fuels, power, steel, cement, automotive and aviation). Section 1 of this paper describes the scope of traditional regulatory stress-tests and reviews past climate stress-testing initiatives, Section 2 provides discussion on why current stress test may not be appropriate and why there is a need for abrupt late $\&$ sudden transition scenarios, Section 3 details the methodology that financial regulators could follow to estimate the impact of a late $\&$ sudden scenario on equity $\&$ bonds in climate-sensitive sectors to provide 'impact tolerance' indicators for markets, portfolios or firms, and Section 4 presents illustrative results obtained by applying this methodology.

\section{Background}

\section{The scope of traditional regulatory stress-tests}

A stress-test can be defined as a 'what-if' analysis that examines the effect of scenarios or sensitivities on the financial position of a bank, or a group of banks." (Cass 2013). Stress-tests are conducted internally by financial institutions as part of their risk management strategy, by regulators as part of the macroprudential policy framework, or by outside actors providing external analysis.

Stress-tests usually consist of three main parts: (i) a qualitative description of several disruptive economic scenarios and how they could propagate to the financial sector, (ii) a list of macroeconomic and sectoral parameters, as well as the values that they would take under each above-mentioned scenario, and (iii) impact indicators reflecting how each scenario impacts the financial sector. The time horizon of the scenarios is usually three years, and the scenario parameters and impact indicators displayed are often limited to a dozen. Table 1 displays the main characteristics of the stress-test conducted yearly by the Fed reserve in the United States, and by the ESRB in Europe.

Table 1. Main characteristics of US \& EU regulatory stress-tests

\begin{tabular}{|c|c|c|}
\hline & Fed reserve stress-test (USA) & ESRB stress-test (EU) \\
\hline $\begin{array}{l}\text { Risk scenarios } \\
\text { considered }\end{array}$ & $\begin{array}{l}\text { - Severe global recession accompanied } \\
\text { by a global aversion for long-term fixed } \\
\text { income assets, leading to a broad-based } \\
\text { and deep correction in asset prices } \\
\text { - Weakening economic activities across } \\
\text { all sectors, accompanied by rapid } \\
\text { declines in long-term rates and } \\
\text { flattening yield curves }\end{array}$ & $\begin{array}{l}\text { - Abrupt and sizeable repricing of risk premia } \\
\text { in global financial markets - triggered e.g. by } \\
\text { a policy expectation shock } \\
\text { - } \quad \text { Adverse feedback loop between weak bank } \\
\text { profitability and low nominal growth } \\
\text { - } \quad \text { Public and private debt sustainability } \\
\text { concerns; } \\
\text { - Liquidity risks in the non-bank financial } \\
\text { sector }\end{array}$ \\
\hline Time horizon & 3 years & 3 years \\
\hline $\begin{array}{l}\text { Macroeconomic \& } \\
\text { sectoral indicators } \\
\text { displayed }\end{array}$ & $\begin{array}{l}\text { GDP growth rate, unemployment rate, } \\
\text { National House Price Index }\end{array}$ & $\begin{array}{l}\text { GDP growth rate, unemployment, HICP, Real } \\
\text { estate prices }\end{array}$ \\
\hline
\end{tabular}




\begin{tabular}{lll}
\hline & Fed reserve stress-test (USA) & ESRB stress-test (EU) \\
\hline $\begin{array}{l}\text { Impact indicators } \\
\text { displayed }\end{array}$ & $\begin{array}{l}\text { Value of the Dow Jones Stock Market Index, } \\
\text { U.S. BBB corporate yield, Projected } \\
\text { loan/revenues/net income losses \& capital } \\
\text { ratios for participating institutions }\end{array}$ & $\begin{array}{l}\text { Stock prices, Long-term rates, Exchange rates, } \\
\text { Foreign demand \& commodity prices, SWAP } \\
\text { rates, Credit spread indices }\end{array}$ \\
\hline
\end{tabular}

Sources: Authors, based on ESRB (2018) \& Board of the Governors of the Federal Reserve System (2018)

\section{A growing interest from regulators for climate stress-testing}

There is a growing debate as to whether climate risks may be material for financial stability. The claim is driven by a solid body of evidence that climate risks may create value destruction for key industrial sectors that are prominently represented in financial markets (e.g. energy, utilities). Indeed, according to Moody's analysis, \$9 trillion of their rated debt may be at immediate or elevated risk of downgrade in response to environmental risks $\left(2^{\circ} \mathrm{II}, 2017 \mathrm{a}\right)$. Around \$15-20 trillion of market capitalization in stock markets is tied up with companies that are covered in the decarbonization scenarios of the International Energy Agency $\left(2^{\circ} \mathrm{II}, 2017 \mathrm{a}\right)$.

As a result, financial supervisory authorities are starting to explore how climate risks - and especially transition risks can be integrated into existing stress-testing frameworks. Associated recommendations around integrating such risks have been put forward by the UNEP Inquiry $\left(2^{\circ} \mathrm{II} /\right.$ UNEP Inquiry 2015), as well as a number of leading think tanks (Bruegel 2016). The European Systemic Risk Board (ESRB) also recommended exploring how transition risks could be integrated into mainstream banking stress-testing frameworks (ESRB 2016). Research initiatives along these lines have been launched by the financial supervisory authorities in Sweden, the Netherlands, United Kingdom, and France ( $\left.2^{\circ} \mathrm{II}, 2015\right)$. We detail hereafter some of the most notable initiatives.

In 2017, Battiston et al. assessed the exposure of European financial institutions to fossil fuel production sectors and energy intensive sectors and analyzed the losses that these institutions would bear assuming an arbitrary $100 \%$ shock in the market capitalization of the fossil fuel sector. They concluded that such a shock to the equity value of the fossil fuel sector wouldn't threaten European financial stability, although specific banks could be significantly impacted.

In the same year, the Dutch Central Bank assessed the potential impact of floods on credit losses and quantified the exposure of Dutch financial institutions to transition risks ("Waterproof? An exploration of climate-related risks for the Dutch financial sector", 2017). This report was followed by another, more in-depth analysis of transition risks and their impact on financial institutions' expected losses ("An energy transition risk stress test for the financial system of the Netherlands", 2018). This latter analysis was conducted using a Computable General Equilibrium model (CGE), whose production functions were modified to reflect the consequences of several transition scenarios, and the macroeconomic impact was then distributed across sectors based on their relative emission intensities.

In 2018, the California Insurance Commissioner's Office conducted, in partnership with the $2^{\circ}$ Investing Initiative $\left(2^{\circ} \mathrm{II}\right)$, a climate scenario analysis of insurance companies operating in California, aiming at quantifying the current and future exposure of these institutions to transitions risks, and physical risks on the asset-side of their balance sheets. However, the impact of these risks, were they to materialize, wasn't quantified. The Bank of England also included the impact of climate change and of a delayed transition in its UK insurers stress tests in 2019, partly based on the methodology presented in this paper. Finally, building on Battiston's 2017 paper, Battiston \& Monasterolo published in 2019 a stress-testing methodology aiming at pricing transition risks in today's value of equity and corporate bonds in the energy \& power sector, as well as in sovereign bonds' value ("A carbon risk assessment of central banks' portfolios under $2^{\circ}$ aligned climate scenarios", 2019).

\section{The choice of the transition scenario}

Many uncertainties remain as to the form that a low-carbon transition would take. The ESRB scientific advisory board's report "Too late, too sudden?" (2016) identified two types of scenario outcomes, a "gradual", smooth ambitious scenario and a late \& sudden one. This concept has been further developed by the UN PRI in 2018 operating under the premise of an "Inevitable Policy Response" (UN PRI, 2018). In addition to the two more ambitious scenarios, transition outcomes could also involve a "do nothing" approach or a limited climate transition ambition, but are of little interest to assess the materiality of transition risks. 
Considering that the purpose of a stress-testing exercise is to assess the impact of a worst-case scenario on the financial system, a late \& sudden scenario is more suited than one that describes a smooth transition. Such a late \& sudden scenario assumes that limited climate action is taken for several years, but is then followed by ambitious action to stay below the $2^{\circ} \mathrm{C}$ threshold by the end of the century. This approach also includes a "sentiment" shock at the moment climate action is taken, leading to a sudden repricing of financial assets.

However, these types of scenarios are yet to be fully explored by macroeconomic or energy-economy models, and little information is available to quantify their economic implications. A project aiming at bridging this gap and commissioned by the PRI is currently underway (PRI, 2019), however this project focuses on establishing alternative baseline scenarios and not 'stress-tests'-type results representing tail risks.

\section{The choice of methodological approaches}

Before estimating the impact of the energy transition on the value of tradable financial assets, the first step is to understand how the profits of companies issuing these securities would be affected by an energy transition, and in particular by a "too late, too sudden" transition. Generally speaking, this can either in top down or bottom up fashion as per Table 2 below.

Table 2. Main approaches used by studies to estimate the impact of transition risks on share prices

TOP-DOWN approach

$\begin{array}{ll}\text { CORE } & \text { Step 1: Using an econometric model to simulate } \\ \text { PRINCIPLE } & \begin{array}{l}\text { macroeconomic variables, among which are global share } \\ \text { prices, under a transition scenario }\end{array}\end{array}$

Step 2: Distribute the global change in equity value among economic sectors according to sector-specific weights

\author{
EXAMPLE CISL "Unhedgeable risks" (2015), DNB "An energy \\ transition risk stress-test for the financial system of the \\ Netherlands" (2018)
}

\section{BOTTOM-UP approach}

Step 1: Estimate, for each sector, the impact of the transition on revenues \& costs, and assess the adaptative capacity of each industry

Step 2: Use a valuation model to estimate the impact of these changes in revenues \& costs on share prices

Ecofys/Navigant "Climate risks of 3 funds of Actiam” (2018), Carbon Delta VaR methodology, ET-Risks

\section{The case for of a standardized framework for climate stress testing and abrupt late \& sudden scenarios}

As highlighted above, methodologies already exist to quantify the exposure of financial institutions' portfolios to climate risks, and first steps have been taken to assess the potential losses that these institutions would incur, were these risks to materialize. The purpose of this paper is to propose 'upgrades' on two fronts. The first is on how climate stress tests are designed and the coordination between the designers and financial supervisors, a call for common parameterisation. The second is on the need for formulation of multiple plausible abrupt late and sudden scenarios, as current stress tests scenarios do not capture the potential effects between macroeconomic indicators, firm specific microeconomic indicators and financial asset evaluation.

To address how stress tests are created, a guiding framework is required to enable cross comparison of scenarios and stress test results. The need for a unified framework or common parametrisation, arises from the lack of capacity across supervisors to develop consistent scenarios using consistent and disclosed inputs as well as methodologies. For example, the information on the activity in the real economy (e.g. the future production and capital expenditure plans of non-financial companies), the relationships of macroeconomic and sectorial indicators (currently based on historical relationships, e.g. oil price and GDP), as well as the relationship between economic and financial indicators (e.g. GDP and non-financial firms' individual revenues).

Trying to predict how the markets might behave in an abrupt late \& sudden low-carbon transition is a daunting task given the lack of precedence and knowledge of the relationship between economic and financial indicators under such circumstances. An approach to address this uncertainty could be by evolving the current research question of "which institutions or markets fail in specific scenarios" to, "how many different scenarios does a financial institution or market show significant stability to solvency concerns". This would both help mitigate the error and uncertainty that arises from the speculative nature of how the markets might behave in abrupt late \& sudden low-carbon transition, 
give an estimation of resilience of financial markets, as well as reduce transaction cost of conducting such assessments.

\section{Abrupt late \& sudden scenarios}

Current scenarios and the assessments that apply them do not capture the anticipated nature of an abrupt late \& sudden decarbonization of global economies on several fronts. Explicitly current assessments do not cover one or more of the follow attributes:

i. The change in sectorial production from non-financial firms (or value) would be non-linear, and the magnitude will accumulate with inaction

ii. There will be strong differentiation in the evaluation of financial assets issued by different non-financial firms in sectors undergoing the transition based on the technologies that each currently deploy or have plans to deploy.

iii. The change in sectorial production and/or revenues would not be cyclic

iv. The change in demand would likely be too sudden to allow market forces act to induce cost-minimized deployment of future supply and it is uncertain how this would be reflected in terms of market sentiment.

Current scenarios that apply a linear shock to a sector or demand from a specific technology fail to capture the true dynamic of an absolute carbon budget that is being continually exhausted and the action that would be required to reduce greenhouse gas concentration. An 'inevitable policy response' would trigger a tipping point in sectoral and/or technological demand, which will manifest itself some point in the future. Consequently, the required magnitude of change accumulates over time as the carbon budget is consumed, and thus greater action is required sooner. As the dependent variable in stress tests is the evaluation of financial assets, which is always a function of future cash flows, when the tipping point occurs will also impact the results independent of the magnitude of shock. Consequently, the time in which the policy response is enacted will have a strong impact on the size of the required response, and testing should be carried out across both size of the shock and when it occurs. To capture this, tests should be conducted across different years to understand how the magnitude of required shock would change to then inform on how market sentiment and price could respond.

The future capacity for non-financial companies to meet demand, and estimations of their future production is available from market intelligence agencies, who track capacity and production at the asset level (Weber, et al. 2017). This data can be used to assess their individual capacity to adapt if late \& sudden scenarios where to materialize. These databases track the purchases of land, permits, and supply chains to be the first to identify corporate activity and sell that to respective industries constituents, as market intelligence. Such data has already been used extensively by financial institutions and supervisory authorities to track the alignment of capital expenditure plans with climate change mitigation commitments, as well and inform on technology level concentrations risk at the portfolio level $\left(2^{\circ} \mathrm{II}, 2017 \mathrm{~b}\right)$. This forward-looking information can be used in conjunction with demand-side production shocks and discounted cashflow modelling to estimate the impact of these shocks on the financial asset prices of each nonfinancial firm in a bottom-up fashion. There benefits of this approach are threefold;

- It incorporates granular firm specific data at the physical asset level that enables the assessment of concentrations risks at a technology level and not just at a sectorial level

- It is informed by future expectations and not just past performance,

- The methodology of formulating/accounting of these expectations is in a consistent manor across each firm in each sector.

In theory this should in turn provide more accurate assessment of non-financial firm solvency and be able to be translated into asset prices and inform financial firms solvency.

The nature of decarbonization of some sectors will not manifest in a cyclical nature as there will be no rebounding for some sectors or some technologies. Traditional stress tests have time horizon of 3 years, assuming cyclicality would imply that companies in transitioning sectors generally have an adaptive capacity to rebound within this time horizon or a traditional business cycle. This does not seem likely for non-financial firms that operate solely in fossilfuel extraction and production for example. An outcome of a stress test should be the degree in which these companies can remain solvent indefinitely given that there is no rebound in sectoral value. 
The change in the evaluation of equity and bonds, the sentiment shock, will not be the direct evaluation of the demand side change currently theorized and represented by traditional integrated assessment models, such as those created by the IEA and members of the Integrated assessment Modelling Consortium. This is because without any early warning system, the tipping point would likely be too sudden to allow market forces act to induce cost minimized deployment of future supply. This especially true within the time frame of traditional stress tests of 3 years. Thus, it is unclear to what extent these scenarios would be reflective of market sentiment if this situation were to occur and although informative for scenario creation, likely will not illustrate the 'worst-case' scenario required to meet the objective of a stress test.

\section{A framework for climate stress testing and developing late \& sudden scenarios}

To the authors' knowledge, there are currently no energy-economy model assessing the consequences of a truly "late \& sudden" scenario on sectoral value-added. The following section outlines an illustrative framework and methodology to build these scenarios using a bottom up approach. First it outlines the framework below in point form, it then illustrates our first attempt in completing such an exercise. Finally, it shows illustrative results of the application of such a framework on two theorical equity and bonds portfolios whose sectoral investments are aligned with the IEA's NPS scenario.

In this paper we have only run one scenario, but the key message of the paper is that many can be run, and that solvency over different scenarios will provide useful insight into market stability and resilience. In addition, although we focus on changes in aggregated sectoral and technological profits for selected indices in this paper, a bottom-up approach also allows total market-level analysis, firm-level analysis as well portfolio level analysis. Consequently, it can inform on both idiosyncratic and systemic sensitivities to late and abrupt decarbonization.

The application framework consisting of the following elements:

i. The call for common parameterisation of the relevant financial indicators that that drive relationship between GHG emissions and firm profits

ii. Identification of the appropriate granularity of the above indicators and sourcing the corresponding business as usual data for each

iii. The formulation of a wide range of plausible abrupt late \& sudden scenarios

iv. Identification of an appropriate evaluation methodology to suit each financial asset class

v. Benchmarking each firm/portfolio or market BAU evaluation against the range of scenarios developed through step iii.

\section{Inputs and Indicators under a business as usual scenario}

The first steps in building the model is to define the relevant data inputs and indicators that drive financial asset evaluation and identify the appropriate granularity and consistent sources for this data under a business as usual scenario. The independent variables calculating the net profit, in simplified terms are production, prices, the fixed and variable costs. Figure 1 below illustrates how transition risks, and particularly those stemming from a "too late, too sudden" transition, would impact carbon-intensive industries' profits across the entire "profit value chain", and details the indicators needed to quantify each of these impacts. 


\section{$\begin{array}{lllll}4 & 2 & 3 & 1\end{array}$}

Net profits $=($ Production volume $*$ Prices $)-$ Costs of Goods Sold - OPex $-($ Taxes + Interests $)$

\begin{tabular}{|c|c|c|}
\hline & How could transition risks impact sectoral profits? & $\begin{array}{l}\text { Indicators needed } \\
\text { to quantify the } \\
\text { impact }\end{array}$ \\
\hline 1 & $\begin{array}{l}\text { Increased cost of emitting CO2: Under a transition scenario, the } \\
\text { implementation of a carbon tax will cut the margin of carbon intensive } \\
\text { industries proportionally to their emissions. Under a "too late, too } \\
\text { sudden" scenario, carbon prices would need to be higher than under a } \\
\text { "smooth" transition scenario, in order to foster a quick decrease in } \\
\text { emissions. }\end{array}$ & $\begin{array}{l}\text { - Production } \\
\text { - Carbon intensity } \\
\text { of production } \\
\text { - Carbon tax }\end{array}$ \\
\hline 2 & $\begin{array}{l}\text { Increased cost of production inputs: During a low carbon transition, } \\
\text { carbon intensive goods will increase in prices due to pass-through of } \\
\text { direct emissions costs. Industries using such carbon intensive goods } \\
\text { as production inputs will thus be impacted. }\end{array}$ & $\begin{array}{l}\text { - Prices of } \\
\text { production inputs }\end{array}$ \\
\hline 3 & $\begin{array}{l}\text { Additional depreciation costs and R\&D expenditures: Under a } \\
\text { transition scenario, significant capital expenditures in low-carbon } \\
\text { technologies will increase companies' annual depreciation costs } \\
\text { (included in Operating Expenses). R\&D expenditures will also likely } \\
\text { increase in the short-term as deployment of new technologies will } \\
\text { have to be expedited to meet the unanticipated demand. }\end{array}$ & $\begin{array}{l}\text { - CAPEX } \\
\text { - R\&D } \\
\text { expenditures } \\
\text { - All other OPEX }\end{array}$ \\
\hline 4 & $\begin{array}{l}\text { Changes in revenues: Companies' revenues will be affected through } \\
\text { a change in prices and consumer demand: As they become } \\
\text { increasingly costly to produce, prices of carbon intensive goods will } \\
\text { likely increase, and consumers will, in turn, decrease their demand for } \\
\text { such goods. A delayed transition, as it would increase the costs bared } \\
\text { by carbon-intensive industries, would likely deepen this effect. }\end{array}$ & $\begin{array}{l}\text { - Production } \\
\text { - Prices }\end{array}$ \\
\hline
\end{tabular}

Figure 1. Impact of transition on sectoral profits \& indicators needed to quantify the impact

A range of initiatives have already sought to quantify the sectoral impacts of a "smooth" energy transition, and provide some indicators allowing to quantify its impact on the profits' determinants detailed in Figure 1. Two relevant initiatives in this regard are the EU H2020-funded ET Risk project and UNEP FI's working group on transition risks (UNEP FI, 2018). To the knowledge of the authors, no research has however yet been conducted to understand the impact on sectoral profits of a delayed transition scenario, although initiatives looking at this issue are under way (notably led by UN Principles for Responsible Investment as part of their "Inevitable Policy Response" work) (PRI, 2018).

Building on this formulation, Table 3 below details the indicators and their data sources that were used to build the "too late, too sudden" scenarios used here. 
Table 3. Sectors included in the analysis and indicators used for profits calculation

\begin{tabular}{|c|c|c|c|c|}
\hline Sector & Target companies & Geography & $\begin{array}{l}\text { Indicators used for } \\
\text { profits calculation }\end{array}$ & $\begin{array}{l}\text { Source of the data for } \\
\text { the BaU \& smooth } \\
\text { transition scenarios }\end{array}$ \\
\hline Oil & Upstream oil & $\begin{array}{l}\text { Europe, North } \\
\text { America, South \& }\end{array}$ & Production, Prices & $\begin{array}{l}\text {-Production data taken } \\
\text { from Asset Resolution, }\end{array}$ \\
\hline Coal & Coal mining & $\begin{array}{l}\text { Central America, } \\
\text { Middle East, Africa, }\end{array}$ & & $\begin{array}{l}\text { IEA WEO2018 SDS \& } \\
\text { NPS }\end{array}$ \\
\hline Natural gas & $\begin{array}{l}\text { Upstream natural } \\
\text { gas }\end{array}$ & Asia Pacific, Eurasia & & $\begin{array}{l}\text { - Prices data taken from } \\
\text { ETP2017 B2DS \& RTS }\end{array}$ \\
\hline Power & $\begin{array}{l}\text { Power generators } \\
\text { (Coal, Gas, Solar, } \\
\text { Wind) }\end{array}$ & $\begin{array}{l}\text { Europe, USA, Latin } \\
\text { America }\end{array}$ & $\begin{array}{l}\text { Production, Prices, } \\
\text { Levelized Cost of } \\
\text { Electricity, } \\
\text { Subsidies }\end{array}$ & $\begin{array}{l}\text { - Production data taken } \\
\text { from Asset Resolution, } \\
\text { WEO2018 SDS \& NPS } \\
\text { - Electricity prices, } \\
\text { LCOE \& Subsidies } \\
\text { taken from ET Risk }\end{array}$ \\
\hline Cement & $\begin{array}{l}\text { Crude steel } \\
\text { producers } \\
\text { Cement producers }\end{array}$ & $\begin{array}{l}\text { Brazil, USA, } \\
\text { Mexico, France, } \\
\text { Germany, Italy }\end{array}$ & $\begin{array}{l}\text { Production, Prices, } \\
\text { Carbon prices, } \\
\text { Carbon intensity }\end{array}$ & $\begin{array}{l}\text { Production data taken } \\
\text { from Asset Resolution, } \\
\text { Prices, carbon prices \& } \\
\text { carbon intensity taken } \\
\text { from ET Risk }\end{array}$ \\
\hline Automotive & Car producers & World average & $\begin{array}{l}\text { Production, Net } \\
\text { margin by } \\
\text { powertrain type }\end{array}$ & $\begin{array}{l}\text { Production data taken } \\
\text { from Asset Resolution, } \\
\text { Production data \& net } \\
\text { margin derived from } \\
\text { ETP2017 \& BNEF }\end{array}$ \\
\hline Aviation & $\begin{array}{l}\text { Airlines } \\
\text { (international) }\end{array}$ & & $\begin{array}{l}\text { Demand, Fuel } \\
\text { efficiency, Fuel } \\
\text { prices }\end{array}$ & $\begin{array}{l}\text { Fleet data taken from } \\
\text { Asset Resolution, } \\
\text { Demand taken from } \\
\text { ETP2017 B2DS \& RTS, } \\
\text { fuel prices \& fuel } \\
\text { efficiency taken from } \\
\text { ET Risk }\end{array}$ \\
\hline
\end{tabular}

\section{Estimating prices and production under an abrupt transition}

Once the baseline values for each of the indicators are defined, the next step is to develop a framework for producing late and sudden scenarios expressed in the terms of the required identified indicators listed above in Table 2.

There many different approaches to estimating future production profiles as well as a plenitude of different outcomes from these models. For instance, the are dozens of integrated assessment models used to inform on the probability of global warming, in part by estimating future production profiles, and thousands of outcomes (Huppmann et al. 2019). Thus, it is anything but certain what the exact production profiles representing global markets undergoing a climate Minsky moment may look like and how they should be formulated. However, for measuring the tolerance of financial markets to these different outcomes, the exact method for producing the production profiles may not need to be so sophisticated. Here we present two simple parameterisation approaches to estimating the future production profiles representing global markets undergoing a climate Minsky moment. 
The first method defines the year in which a production shock occurs, and the duration of this shock, and how large for each technology undergoing transition. After which the production trajectory resumes the profile of current IAM estimations of future demand. The intent of this style of approach, would be purely understanding how financial asset prices may react under modification of parameters independent on what the consequences may be for emissions, as well as the impact of those emissions on future demand.

The second approach attempts to use a global carbon budget accounting approach that approximates keeping GHG emissions within roughly within $450 \mathrm{ppm}$, albeit in a very simplified manor (further detailed in Annex A). The intent of this approach is to simulate the outcome of a policy response that manages to maintain a likely probability of limiting global warming to within 2 degrees by the turn of the century, i.e. stylizing an attempt to meet the Paris Agreement, assuming the policy action occurs somewhere between 2025-2035.

Using the first model to understand a market, firm or portfolios' sensitivity to a climate Minsky moment in general, requires that the production profiles for each region and technology to be iterated over the parameter for size of the shock, when the shock occurs, and its duration. The evaluation of the impact of this production/demand side shock then informs financial asset pricing through DCF modeling and bond default probability and pricing models. Similarly, for the second model, the year of the shock and the assumed 'climate lag', the residence time for emitted $\mathrm{CO}_{2}$ in the atmosphere, would be iterated over suitable range of values. The results could be representing in simple matrices that illustrate the tolerance of a market, firm or portfolio to the combinations of shock magnitude and climate Minsky year for each technology or sector.

Although both approaches described above represents a valuable first step in the development of "too late, too sudden" transition scenarios, there are several caveats to bear in mind. First, the approaches overlook possible interactions between sectors (in reality, emissions may decrease less than needed in an industry and more than needed in another) - although it takes into account risk propagation across industries (e.g. an increase in oil prices impacts airlines expenses). Second, in the absence of alternative solutions, it features a very simplistic price dynamic. Finally, in the absence of alternative solutions, it neglects changes in net margins for some sectors. In both methods however, all other indicators within Table 3 could be also be varied to help understand if the uncertainty in their estimations flow through to impact evaluation at the market, portfolio, or firm level.

\section{Estimating equity value under a "too late, too sudden" transition scenario}

As explained above, the energy transition will impact companies' revenues and expenses, with the amplitude of the effect varying depending on the sector they operate in, which market the operate, and when the shock occurs. These changes in the companies' profits will subsequently impact their market value, as the demand for shares issued by weaken companies will decrease. We rely on standard evaluation approaches to capture these changes.

To estimate changes in share prices under a "too late, too sudden" scenario, we rely on Gordon's formulation of future dividends' flows (Gordon 1959). The equity market price $V_{E}$ at time $t_{0}$ is given by:

$V_{E, t_{0}=\frac{D_{1}}{r-g}}$ with $D_{1}$ being the expected dividends for the next year, $r$ being the cost risk of capital for the company, and $\mathrm{g}$ being the dividend's growth rate.

Assuming dividends for a given year are proportional to the net profits of the company for this year, and explicitly modeling the future evolution of profits, we derive the following formula:

$V_{E, t_{0}}=\alpha \sum_{t=t_{0}}^{t_{b}} \frac{P_{t}}{(1+r)^{t}} *(1+x)$

With $P_{t}$ being the profits made by the company in year $t$ (modelled as explained in Section 2.1), $t_{b}$ the date until which we explicitly model cash-flows, $x$ the percentage of modelled value in the terminal value, and $\alpha$ the proportionality coefficient between net profits and dividends.

In simple words, the value of equity for a given company is assumed to equate the Net Present Value of its future cash-flows. The difference between $V_{\mathrm{E}, \mathrm{t} 0}$ under the Business as Usual and the "too late, too sudden" scenarios is the equity value put at risk by the transition. 
Estimating corporate bonds ' value under a "too late, too sudden" transition scenario

The most influential factors that affect a bond's market value are its yield, prevailing interest rates (as they affect the discount rate of the bond's cash flows) and the bond's probability of default. For simplicity we don't hypothesis how a "late \& sudden" transition would affect inflation and thus long-term interest rates and therefore, our application we focus on default-risk as the sole driver of bond value changes under a transition scenario. Discount rates are kept constant across all scenarios.

\section{Estimating the probability of default under a transition scenario}

There are many methods used calculate in credit risk, each require different assumptions and data, and ultimately have various forecasting accuracies (Tanthanongsakkun, et. al, 2009). Commercial credit rating typically employs derivates of the Merton distance-to-default model (e.g. Moody's KVM and Bloomberg's credit risks models). Nonetheless it is clear that bonds' probabilities of default are heavily correlated with the main financial ratios of their issuers (Tang \& Yan, 2010).

For sake of computational convenience, we employ Zmijewski's (1984) bankruptcy model to calculate the change in probability of default at time $t$ under a business as usual scenario and then over the range of late $\&$ too sudden scenarios. We then apply this change in default probability to commercially published default probabilities, at security level. This helps to calibrate the results based on exogenous risks not captured within our framework and is assumed to compensate for some of our simplifications.

To apply Zmijewski's model we assume that a change of a $x \%$ in net income translates into an $x \%$ change in NI/TA. In addition, we simplify to assume that both the total liabilities and current assets are assumed constant over time, and thus in accordance to Zmijewski, the bond defaulting at a certain time $t$ can be express as:

$D_{t}=\varphi\left(-4.336-4.513 \frac{N I_{t}}{T A}+5.679 \frac{T L}{T A}+0.004 \frac{C A}{C L}\right)$

Where $P D$ is the 1-year probability of default, $\varphi$ the standard normal cumulative distribution function, NI/TA net income over total assets, $T L / T A$ total liabilities over total assets, and $C A / C L$ current assets over current liabilities.

Taking the limitations of Zmijewski's model into account, the changes in NI/TA over time are used to calculate the changes in PD over time:

$\Delta P D_{t}=P D_{t}-P D_{t-1}$

The probability of default for each bond in the market or index is then the product of $\triangle P D_{t}$ and the bonds current probability of default in time $t$.

\section{Estimating the value of a bond under a transition scenario}

The value of a bond is then given by probability weighted discounted cash flow represented by:

$V_{j}=\sum_{t=1}^{T} X_{t} P D_{t}\left(\prod_{k=0}^{t-1}\left(1-P D_{k}\right)\right)$

With $V_{j}$ being the value of bond $j, T$ being the maturity date of the bond, $X$ represent the net present value of a bond's cash flow (defined below), and $P D_{t}$ being the probability of default computed in Section 2.4.1.

Where the net present value of the bonds future cash flows is given by:

$X_{T}=\sum_{t=1}^{T} \frac{C_{j} F_{j}}{\left(1+r_{j}\right)^{t}}+\frac{F_{j}}{\left(1+r_{j}\right)^{T}}$

Where $F_{j}$ is the face value of the bond $j, C_{j}$ is the coupon rate of the bond $j, R$ is the recovery rate in case of default, $r_{j}$ is the discount rate for the cash flows.

For a bond expected to mature in $T$ time periods, with coupons paid every period, the present value of its cash flow stream, assuming no default, can be written as: 
$V_{j}=$

$\sum_{t=1}^{T} \frac{C_{j} F_{j}}{(1+r)^{t}}\left(\prod_{k=1}^{t}\left(1-P D_{k}\right)\right)+R_{j} F_{j} \sum_{t=1}^{T} \frac{P D_{t}}{(1+r)^{t}}\left(\prod_{k=0}^{t-1}\left(1-P D_{k}\right)\right)+\frac{F_{j}}{(1+r)^{T}} \prod_{k=1}^{T}\left(1-P D_{k}\right)$

In the example displayed in Section 3 below, we set $R_{j}=38 \%{ }^{1}, F_{j}=1000, C_{j}=5 \%, r=5 \%$.

\section{Illustrative Results}

In this section, we display some results obtained for only one scenario, using the GHG concentration driven stylized late \& sudden scenarios developed in Annex A. A key objective of the paper is to display multiple results from multiple simulations to inform on the key risk drivers and their sensitivities, but the results are of which currently not available at the time of publishing.

The results below outline the changes in the mean equity value of companies in key sectors under a "late \& sudden" transition scenario, assuming a sudden repricing due to a market sentiment shock when the transition starts, are displayed in Table 3 (World average). As for corporate bonds, Table 4 illustrates the increase in the mean 1-year probability of default of bonds tied to sensitive sectors, 1 year and 10 years after the beginning of a "late \& sudden" transition (World average). Table 5 displays the change in the value of an illustrative bond with a face value of $1000 \$$, a $5 \%$ coupon rate, and a $38 \%$ recovery rate, depending on the sector it is tied to, and depending on its remaining time to maturity after the "late \& sudden" transition starts (in 2025).

We set $r=5 \% ; t_{0}=2025$ (i.e. we assume a sudden repricing of equity in 2025, date at which the TLTS transition starts, due to a market sentiment shock), $t_{b}=2040, x=10 \%$ and $\alpha=1$ for all scenarios.

Table 4. Mean change in equity value compared to a BaU scenario ${ }^{2}$ under a "too late, too sudden" transition scenario for key sectors, assuming a sudden repricing in $2025(\%)$

\section{Change in equity value $(\%)$}

\begin{tabular}{lc}
\hline Upstream Oil & $-53.3 \%$ \\
Coal mining & $-57.0 \%$ \\
Upstream gas & $-30.8 \%$ \\
Coal electricity & $-80.1 \%$ \\
Gas electricity & $-20.3 \%$ \\
Solar PV & $19.2 \%$ \\
Wind electricity & $12.8 \%$ \\
Nuclear & $19.9 \%$ \\
Crude steel & $-52.0 \%$ \\
Cement & $-27.0 \%$ \\
Automotive & $-9.5 \%$ \\
Aviation & $-21.0 \%$ \\
\hline
\end{tabular}

\footnotetext{
${ }^{1}$ Historical recovery rate of senior bonds (Moody's, 2017)

2 Corresponding to IEA's NPS \& RTS scenarios
} 
As expected, upstream fossil fuel industrials and fossil-based power producers, in particular coal electricity producers, are the most strongly hit by the transition, while listed renewable energy producers enjoy a significant revaluation of their shares.

It is worth noting that these results are sectoral averages, and thus do not consider the adaptative capacities of individual companies that the proposed model can and should produce. This aggregated impact on sectoral equity value might hide significant disparities between companies of a given sector. As, in the context of regulatory stresstesting, changes in the value of entire asset classes are of more interest than changes in individual asset values, this isn't much of a concern. Our flexible bottom-up approach to estimating changes in sectoral profits, detailed in Section 2.1, could however be adapted to uncover these disparities. Global production trends taken from the IEA could be broken down to company level using a fair-share approach, while indicators related to energy efficiency and operating margin could be estimated on a case-by-case basis, based on the CAPEX and R\&D expenditures already engaged by the company. Such an approach would enable the assessment of the consequences of the transition on companies with mixed revenue streams (e.g. revenues from carbon intensive and renewable power production at the same time) (The CO FIRM, ClimateXcellence, 2018).

Table 5. Mean 1-yr probabilities of default of bonds issued by climate-sensitive sectors under a "too late, too sudden" transition scenario $(\%)$

\begin{tabular}{lccc}
\hline Steel & $\begin{array}{c}\mathbf{2 0 1 8} \\
\text { (Baseline†) }\end{array}$ & $\mathbf{2 0 2 6}$ & $\mathbf{2 0 3 5}$ \\
Cement & 0.03 & 0.03 & 0.06 \\
Oil & 0.02 & 0.02 & 0.05 \\
Coal & 0.01 & 0.03 & 0.06 \\
Gas & 0.02 & 0.04 & 0.09 \\
Coal power & $0.02^{*}$ & 0.04 & 0.05 \\
Gas power & & 0.02 & 0.09 \\
Nuclear & & 0.02 & 0.00 \\
Solar PV & & 0.02 & 0.00 \\
Wind & & 0.01 & 0.00 \\
Airlines & 0.03 & 0.04 & 0.06 \\
Automotive & 0.01 & 0.01 & 0.02 \\
\hline
\end{tabular}

† Bloomberg default probabilities data, Q4 2018

* Mean 1yr probability of default of power producers worldwide in Q4 2018 (Source: Bloomberg) 
Table 6. Mean change in bond values compared to baseline under a "too late, too sudden" transition scenario, depending on their remaining time to maturity, and assuming a sudden repricing in 2025 (\%)

\begin{tabular}{lcccccccccc}
\hline & $\mathbf{1}$ & $\mathbf{2}$ & $\mathbf{3}$ & $\mathbf{4}$ & $\mathbf{5}$ & $\mathbf{6}$ & $\mathbf{7}$ & $\mathbf{8}$ & $\mathbf{9}$ & $\mathbf{1 0}$ \\
\hline Steel & $-0.2 \%$ & $-0.7 \%$ & $-1.2 \%$ & $-1.9 \%$ & $-2.6 \%$ & $-3.3 \%$ & $-4.1 \%$ & $-4.9 \%$ & $-5.7 \%$ & $-6.5 \%$ \\
Cement & $-0.2 \%$ & $-0.5 \%$ & $-1.0 \%$ & $-1.5 \%$ & $-2.2 \%$ & $-2.9 \%$ & $-3.8 \%$ & $-4.7 \%$ & $-5.6 \%$ & $-6.6 \%$ \\
Oil & $-1.4 \%$ & $-2.9 \%$ & $-4.6 \%$ & $-6.4 \%$ & $-8.3 \%$ & $-10.0 \%$ & $-11.7 \%$ & $-13.3 \%$ & $-14.8 \%$ & $-16.2 \%$ \\
Coal & $-0.8 \%$ & $-1.9 \%$ & $-3.2 \%$ & $-4.6 \%$ & $-6.2 \%$ & $-7.7 \%$ & $-9.2 \%$ & $-10.6 \%$ & $-12.0 \%$ & $-13.1 \%$ \\
Gas & $-0.5 \%$ & $-1.1 \%$ & $-1.9 \%$ & $-2.9 \%$ & $-3.9 \%$ & $-5.0 \%$ & $-6.1 \%$ & $-7.2 \%$ & $-8.2 \%$ & $-9.3 \%$ \\
Coal power & $-1.1 \%$ & $-2.5 \%$ & $-4.2 \%$ & $-6.2 \%$ & $-8.4 \%$ & $-10.2 \%$ & $-12.1 \%$ & $-13.8 \%$ & $-15.5 \%$ & $-17.1 \%$ \\
Gas power & $-0.4 \%$ & $-0.8 \%$ & $-1.2 \%$ & $-1.6 \%$ & $-2.1 \%$ & $-2.8 \%$ & $-3.5 \%$ & $-4.2 \%$ & $-5.0 \%$ & $-5.7 \%$ \\
Nuclear & $0.1 \%$ & $0.3 \%$ & $0.6 \%$ & $0.9 \%$ & $1.4 \%$ & $1.8 \%$ & $2.4 \%$ & $3.0 \%$ & $3.7 \%$ & $4.4 \%$ \\
Solar PV & $0.4 \%$ & $1.1 \%$ & $2.2 \%$ & $3.5 \%$ & $4.6 \%$ & $5.6 \%$ & $6.6 \%$ & $7.6 \%$ & $8.5 \%$ & $9.3 \%$ \\
Wind & $0.3 \%$ & $0.9 \%$ & $1.7 \%$ & $2.8 \%$ & $4.0 \%$ & $5.1 \%$ & $6.1 \%$ & $7.0 \%$ & $7.9 \%$ & $8.8 \%$ \\
Airlines & $-0.2 \%$ & $-0.6 \%$ & $-1.2 \%$ & $-1.9 \%$ & $-2.6 \%$ & $-3.4 \%$ & $-4.2 \%$ & $-5.1 \%$ & $-5.9 \%$ & $-6.7 \%$ \\
Automotive & $-0.2 \%$ & $-0.5 \%$ & $-0.8 \%$ & $-1.1 \%$ & $-1.3 \%$ & $-1.5 \%$ & $-1.8 \%$ & $-2.1 \%$ & $-2.4 \%$ & $-2.7 \%$ \\
\hline
\end{tabular}

As illustrated by Table 4 and Table 5, the bond value that is put at risk by a "late \& sudden" transition increases as a function of the time to maturity of the bonds, driven by a rise in their 1-year probability of default as the transition progresses. As highlighted above for equity, Coal \& Oil producers, as well as Coal power producers are the most strongly affected by a late $\&$ sudden transition.

\section{Caveats}

Although the approach developed above represents a valuable first step in the development of a "too late, too sudden" transition scenario that could be used by financial supervisors as an input into climate stress-tests of regulated entities, there are several caveats to bear in mind.

First, the methodology that we developed in Section 2.2 to estimate the impact of a late \& sudden transition on sectoral profits suffers some limitations - as detailed in Section 2.2.: it overlooks some possible interactions between sectors, it considers a simplistic price dynamic, and it neglects changes in net margins for some sectors. The approach developed in this paper fills a gap - the absence of a proper late \& sudden transition 'stress-test' scenario including the indicators needed to estimate the changes in sectoral profits, but it shouldn't be considered sufficient. A proper late \& sudden scenario developed by the energy-economy modelling community, granular both at geography and sectoral levels, would to take climate stress-testing a step further. The Inevitable Policy Response project, led by the PRI, will likely fill this gap. But still multiple scenarios covering different potential outcomes and tools that enable easy assessment of both markets and portfolios should be developed.

Second, the methodology that we developed to assess the changes in bond and equity value for companies in carbon-intensive sectors doesn't consider potential mixed revenue streams, they apply to theorical companies with all their revenues coming from only one carbon-intensive sector. When applying the equity and bond shocks estimated above to investment portfolios, a solution would thus be to compute an average shock for each company in the portfolio, weighed by the share of their revenues coming from each carbon-intensive sector. Alternatively, as mentioned pg. 12, our methodology could also be applied at company-level and directly factor mixed revenue streams into future profits calculations. 
Third, this paper doesn't cover sovereign bonds. This is because contrary to Battiston \& Monasterolo (2019), we do not consider that a correlation between short-term GDP changes and sovereign interest rates is clearly established in literature, either in developed or emerging economies (IMF, 2012; G.Min, 1999), let alone did we find a value to use for the sensitivity factor. Fiscal indicators, in turn, are designated by the literature as key drivers of sovereign bonds' interest rates, but the methodology developed in this paper doesn't yet allow us to quantify the changes in a country's indebtedness under a late \& sudden transition scenario. A next step would thus be to investigate the relationships between profits of carbon-intensive sectors and fiscal revenues and understand how shocks to the valueadded of these sectors would impact a country's dept-to-GDP ratio.

\section{Conclusion}

To respond to the growing demand for supervisors to be able to answer questions on the materiality of transitions risks posed to financial markets in a late and sudden decarbonization of economies, this paper first highlights the inadequacy of current approaches. The shortfalls of applying traditional stress testing for assessing systemic risk, to assessing risk associated with sudden economic decarbonization, lie in the lack of use of available information on the future capital expenditure plans of non-financial companies, the inadequacy of the time horizon of traditional tests leading to implicit assumptions about the rebounding of sectoral value, and the lack of abrupt late \& sudden scenarios to test against.

To combat this, the paper proposes that risk assessment should be carried out via sensitivity analysis producing 'impact tolerance' indicators. Assessing a range of possible futures could mitigate uncertainty around how market sentiment may respond to an inevitable policy response. Given that this sort of test does not exist, nor the scenarios, we demonstrate how this could be done by: (1) building "late \& sudden" transition scenarios including all the indicators needed to estimate future changes in profits of carbon-intensive sectors, that can also be calibrated to reflect the current climate trajectory of any investment portfolio, (2) demonstrating how a to price the risks associated with a late $\&$ sudden transition into equity and corporate bonds' value, and (3) and finally by empirically demonstrating the need, by estimating and showing the risk associated with a late $\&$ sudden transition might have a significant impact on equity and bond value of companies in carbon-intensive sectors, fossil fuels extraction and coal-based power production being the most threatened activities.

Combining the methodology developed above with an analysis of the exposure of financial institutions to carbon intensive sectors would allow financial supervisors to assess the potential impact of a "late \& sudden" transition on financial stability. Such a combination of top-down stress-tests and exposure analysis through asset-level data has been pioneered in the Bank of England's 2019 insurance stress-test, which was informed in part by the results presented above. This methodology will also be applied by the $2^{\circ}$ Investing Initiative in their partnership with the European Insurance and Occupational Pension Authority (EIOPA) in 2019.

\section{References}

$2^{\circ}$ II. (2017a). "Right direction, wrong equipment".

$2^{\circ}$ II. (2017b). "Out of the fog: Quantifying the alignment of Swiss pension funds \& insurances with the Paris Agreement".

$2^{\circ}$ II. (2016). "Transition Risk Toolbox".

$2^{\circ}$ II. (2015). "Financial risk and the transition to a low-carbon economy: towards a carbon stress testing framework"

$2^{\circ}$ II. (2014). "Carbon risks for financial institutions".

$2^{\circ} \mathrm{II}$; The CO FIRM. (2017). "Transition risk-O-meter".

$2^{\circ}$ II; UNEP FI; WRI (2015). "Climate strategies and metrics. Exploring options for institutional investors".

Alexius, A., \& Sp, D. (2018). Stock prices and GDP in the long run, 8(4), 107-126.

Battiston, S., Mandel, A., Monasterolo, I., Schuetze, F., \& Visentin, G. (2015). A Climate stress-test of the EU financial system, $1-12$.

Cantor, R., \& Packer, F. (1996). Determinants and Impact of Sovereign Credit Ratings, 37-54.

CISL. (2015). Unhedgeable risk.

De Nederlandsche Bank. (2018). An energy transition risk stress test for the financial system of the Netherlands.

De Greiff, K., Delis, M., \& Ongena, S. (2018), "Being Stranded on the Carbon Bubble? Climate Policy Risk and the Pricing of Bank Loans", CEPR Discussion Papers (May 2018).

Dudian, M., \& Popa, R. A. (2012). Analysis on the Relationship between Rating and Economic Growth for the European Union Emergent Economies, 6(4), 431-434.

Ecofys. (2018). Climate risks of 3 funds of Actiam.

ESRB. (2016). "Too late, too sudden: Transition to a low-carbon economy and systemic risk". 
ESRB. (2018). "Adverse macro-financial scenario for the 2018 EU-wide banking sector stress test”.

FED reserve. (2018). Dodd-Frank Act Stress Test 2018: Supervisory Stress Test Methodology and Results, (June).

Huppmann et al (2019), Dannel Huppmann, Elmar Kriegler, Volker Krey, Keywan Riahi, Joeri Rogelj, Katherine Calvin, Florian Humpenoeder, Alexander Popp, Steven K. Rose, John Weyant, Nico Bauer, Christoph Bertram, Valentina Bosetti, Jonathan Doelman, Laurent Drouet, Johannes Emmerling, Stefan Frank, Shinichiro Fujimori, David Gernaat, Arnulf Grubler, Celine Guivarch, Martin Haigh, Christian Holz, Gokul Iyer, Etsushi Kato, Kimon Keramidas, Alban Kitous, Florian Leblanc, Jing-Yu Liu, Konstantin Löffler, Gunnar Luderer, Adriana Marcucci, David McCollum, Silvana Mima, Ronald D. Sands, Fuminori Sano, Jessica Strefler, Junichi Tsutsui, Detlef Van Vuuren, Zoi Vrontisi, Marshall Wise, and Runsen Zhang. 'IAMC 1.5 $\mathrm{C}$ Scenario Explorer and Data' IIASA, Integrated Assessment Modeling Consortium \& International Institute for Applied Systems Analysis, 2019. doi: 10.5281/zenodo.3363345 | url: data.ene.iiasa.ac.at/iamc-1.5c-explorer

International Energy Agency. (2017). World Energy Outlook.

International Energy Agency. (2017). Energy Technology Perspectives 2017.

Internation Monetary Fund. (2012). Long-Run and Short-Run Determinants of Sovereign Bond Yields in Advanced Economies. IPCC. (2018). Special report on global warming of $1.5^{\circ}$.

Jakob, M., Luderer, G., Steckel, J., Tavoni, M., \& Monjon, S. (2012). Time to act now? Assessing the costs of delaying climate measures and benefits of early action, 79-99. https://doi.org/10.1007/s10584-011-0128-3

Johnson, N., Riahi, K., Kriegler, E., Johnson, N., Bertram, C., \& Elzen, M. Den. (2013). Locked into Copenhagen pledges Implications of short-term emission targets for the cost and feasibility of long-term climate goals Technological Forecasting \& Social Change Locked into Copenhagen pledges - Implications of short-term emission targets for the cost and feasibility of long-term climate goals. Technological Forecasting \& Social Change, (January 2014). https://doi.org/10.1016/j.techfore.2013.09.016

Hong G. Min. (World Bank). (1999). Determinants of emerging market bond spread: do economic fundamentals matter?

Moody's. (2015). Heat Map Shows Wide Variations in Credit Impact Across Sectors.

OECD. (2017). Investing in Climate, Investing in Growth.

PRI. (2019). Inevitable Policy Response: Policy Forecasts

Ravina, A. (2017). Assessing transition risk with a stress test methodology, (2013), 1-18.

S\&P. (2016). 2016 Annual Global Corporate Default Study And Rating Transitions.

S\&P. (2019). Connecting the dots: Energy transition scenarios and credit quality.

S\&P. (2015). How Environmental And Climate Risks Factor Into Global Corporate Ratings.

S\&P. (2017). How Environmental And Climate Risks And Opportunities Factor Into Global Corporate Ratings - An Update.

Tang, D.Y., \& Yan, H. (2010). Market conditions, default risk and credit spreads. Journal of Banking and Finance, 34(4), 743753. https://doi.org/10.1016/j.jbankfin.2009.05.018

Tanthanongsakkun, Suparatana; Pitt, David; Treepongkaruna, Sirimon (2009), A Comparison of Corporate Bankruptcy Models in Australia: the Merton vs Accounting-based models, Asia-Pacific Journal of Risk and Insurance, vol. 3(2), April. Pg. 1-21

The CO FIRM; Kepler Cheuvreux. (2018). Investor primer to transition risk analysis.

The CO FIRM; ClimateXcellence. (2018). Climate scenario analysis: cement's financial performance under $2^{\circ} \mathrm{c}$ and $2.7^{\circ} \mathrm{c}$

Thomä, J. Dupré, S. Hayne, M. (2018). A Taxonomy of Climate Accounting Principles for Financial Portfolios. Sustainability 2018, 10(2), 328; https://doi.org/10.3390/su10020328

Weber, C., Hayne, M., Dupré, S., Thomä J. and Braschi, T. (2017), “Asset-level data and climate-related financial analysis: A market survey" available at: http://2degrees-investing.org/IMG/pdf/assetdata_v0.pdf (accessed 15 January 2018).

UNEP FI; Mercer. (2018). Extending our horizons.

UN PRI. (2018). The inevitable policy response: Act now.

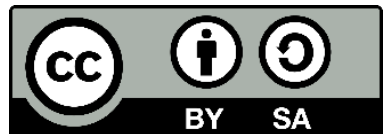

(C) 2019 by the authors. Licensee ACRN Publishing, Austria, Editor in Chief Prof. Dr. Othmar M. Lehner. This article is an open access article distributed under the terms and conditions of the Creative Commons Attribution (CC BY SA) license (https://creativecommons.org/licenses/by-sa/4.0/) 


\section{ANNEX A: Detailed methodology for GHG concentration driven stylized late \& sudden production curves}

This annex outlines the assumptions used to derive an approximated production curves used to illustrate the general methodology of stress testing late \& sudden scenarios.

\section{Production \& efficiency:}

- For each sector, the additional emissions occurring before the start of the transition under a delayed action scenario compared to a smooth transition scenario (date at which the transition starts) need to be offset if the Minsky moment is intended to capture a market sentiment of actualize the Paris Agreement (i.e. limiting global warming by 2 degrees or less by the turn of the century). Thus, the timing of the Minsky moment is a key independent variable, and markets and portfolio should be tested across a range of time horizons. In our simulation, we chose to model production out to by 2040, and assumed a climate lag of 60 years (the temperature of 2100 is determined by the GHG emitted 60 years before).

- How these emissions are offset is dependent on the sector. Generally speaking offsetting can achieved through either reducing production, increasing efficiency, or offsetting by carbon removal activities will impact the relationship between production and profit. Which route emission reduction take is based on the function of each sector the global economy. For example, cement being an essential material to build the infrastructures needed for the 10 billion humans expected by 2050, assuming a major drop in production would seem unlikely (as illustrative in IAM e.g. the IEA in ETP 2017), a surge in energy efficiency due to sudden R\&D efforts seems more realistic (or the development of a substitution product, but we didn't consider this possibility in the paper).

- The offsetting can either be done at economy level, i.e. considering the emissions occurring in each sector before 2025 in the IEA New Policy Scenario (or any other global Business as Usual scenario of this kind) or done at the portfolio level, using tools such as the Paris Agreement Capital Transition Assessment (PACTA) Transition Monitor ${ }^{3}$. The tool quantifies the current exposure of investment portfolios to "climate-relevant" sectors and technologies (Fossil fuels - Oil, coal, natural gas; Power - Coal, gas, renewables; and Automotive - Electric vehicles, hybrid vehicles, ICE vehicles) and provides a forward-looking assessment of its alignment with $2{ }^{\circ} \mathrm{C}$ scenarios (based on the production and investment plans of the companies financed by the portfolio). The emissions occurring before the start of the transition, which have to be offset afterwards, will thus reflect the production that is currently funded by the portfolio, and its expected evolutions in the next 5 years. That way, the shocks applied to the portfolio are calibrated to its current trajectory.

The results displayed in this paper are based on the "global market" approach (i.e. the production in each sector before the start of the transition follows the NPS scenario).

Figure 2 below illustrate these principles for the coal mining sector:

\footnotetext{
${ }^{3}$ See https://www.transitionmonitor.com/ for more details
} 


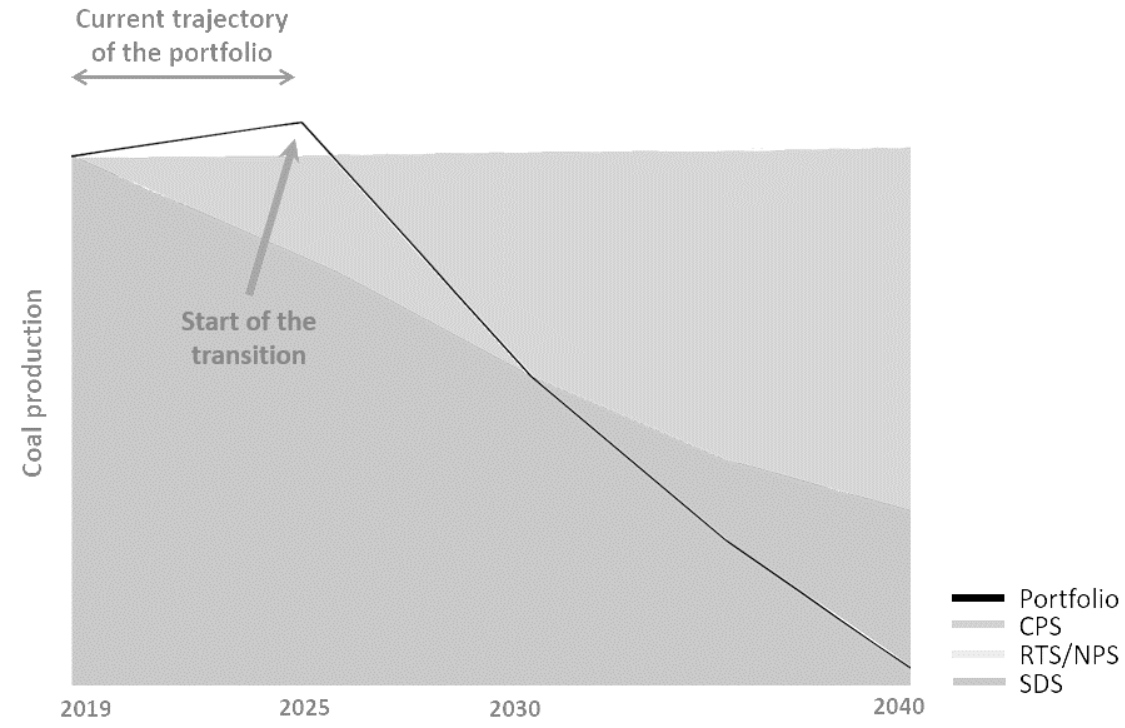

Figure 2. Illustrative trajectory of the coal production financed under a delayed transition scenario starting in 2025

Prices and profit margins:

- Fossil fuel prices under a delayed transition scenario evolve proportionally to demand; prices for other sectors slowly reach the levels of a "smooth" transition once the "late \& sudden" transition starts.

- No impact on gross or operating margins is assumed for building material industries (Steel \& Cement), as the authors didn't find any reasonable way to estimate this under a delayed transition scenario. The impact that a delayed transition would have on profits for these sectors might thus be underestimated.

- In line with literature, ${ }^{4}$ carbon prices are assumed to be 1.5 times higher in 2040 under a "too late, too sudden" scenario compared to a "smooth" transition scenario, to foster quicker energy efficiency improvements once the late \& sudden transition has started.

Although the approach developed above represents a valuable first step in the development of "too late, too sudden" transition scenarios, there are several caveats to bear in mind. First, the approach overlooks possible interactions between sectors (in reality, emissions may decrease less than needed in an industry and more than needed in another) - although it takes into account risk propagation across industries (e.g. an increase in oil prices impacts airlines expenses). Second, in the absence of alternative solutions, it features a very simplistic price dynamic. Finally, in the absence of alternative solutions, it neglects changes in net margins for some sectors.

\footnotetext{
${ }^{4}$ See Advance_2020_Med2C (“smooth" transition scenario) and Advance_2030_Med2C (slightly delayed transition scenario)
} (https://data.ene.iiasa.ac.at/iamc-1.5c-explorer/) 